\title{
Research on the Construction of School Physical Education and Its Evaluation System
}

\author{
Zhi Li \\ Xi`an University, Xi`an, Shaanxi, 710065
}

Keywords: Physical Education, Evaluation System, Construction Method.

\begin{abstract}
With the smooth progress of the new round of basic education curriculum reform, our country's physical education teaching thought and the physical education teaching mode have undergone profound changes. These changes urgently require the establishment of the corresponding PE teaching evaluation system to reform and urgently need to solve the theory and practice Between the contradictions in order to ensure and promote the further development of China's physical education reform. Based on the theory of pedagogy, evaluation and physical education, this paper aims to reveal the main characteristics and internal laws of PE teaching evaluation, and put forward the theoretical basis of constructing PE teaching evaluation system and establish the evaluation of PE teaching The content and weight of the index system, the design of sports teaching evaluation program, from the theory and practice at the two levels to solve the problem of operability evaluation of physical education teaching methods.
\end{abstract}

\section{Introduction}

Education is "cultivating a social phenomenon", is to make natural people become extremely serious social career, is to pass the experience of production and social life experience the necessary means. The process of education is first a process of spiritual growth and then becomes part of the process of scientific knowledge. Therefore, education is the exchange and understanding, is to enhance the quality of life process. For school education, its purpose has always been to students' growth and development, is the history of human spiritual content into today's vibrant spirit, and through this spirit to guide all students to master the knowledge and technology. School education is the most important part of the education of people's life, students in the school to accept the planned guidance, systematic learning of cultural knowledge, social norms, moral standards and values. School education in a sense, determines the level and nature of individual socialization, is an important base for individual socialization. Therefore, the responsibility of school education is significant, which requires a means to test the effectiveness of education, this means is the evaluation of education. In the system of school education, educational evaluation is an important part of all educational activities. It is an indispensable part of education. It is the realization of educational goals, the development and reform of education, and the education management and decision-making. Crucial role.

\section{Evaluation of Physical Education}

Evaluation of Physical Education Teaching is an Evaluation of the Complete Process of Physical Education Teaching. The evaluation of PE teaching is the concrete application of teaching evaluation theory in physical education teaching, which is the concrete manifestation of general evaluation activities in sports field. For a complete and effective teaching process of physical education, teaching evaluation is an indispensable part of the process of physical education, it has the physical education teaching activities and its effect to judge, through the feedback process of information feedback to ensure that physical education teaching activities to achieve physical education The function of the goal is based on the established goal of physical education, the use of teaching evaluation theory, methods and techniques, systematically and scientifically collect and 
deal with physical education teaching information, the physical education teaching design, teaching process and teaching results of the objective description process, The process of value judgments, the process of psychological isomorphism. The evaluation of physical education is of vital importance to the development and reform of physical education and the management and decision-making of physical education. As an important tool to measure the effect of physical education teaching, the evaluation of physical education can not only reveal the right and wrong, reasonable and unreasonable in the teaching of physical education, but also have the guidance and the promotion of the work of physical education to the right Direction of the role of development. It is directly related to the design of teaching objectives, the renewal of teaching ideas, the use of teaching methods, the choice of teaching content and many other theoretical and practical processes.

\section{Establish the Evaluation Index System of Physical Education}

"Indicators" is the measure of the quality of the object and the number of items. It reflects the recognition angle of the evaluation object or the size range of the content coverage. It not only clarifies the concept of the characteristic of the evaluation object, but also the quantity of the evaluation object, which is the qualitative orientation of the behavior of the evaluation object, With a qualitative understanding and quantitative understanding of the dual role. Different evaluation of the object, from different angles or content to evaluate. Objective and comprehensive understanding of the object to be recognized, should take a multi-angle choice. According to the needs of evaluation tasks and evaluation objectives, it is an evaluation index system that can comprehensively and systematically reflect a series of relatively complete and effective teaching evaluation indexes of a specific evaluation object. Evaluation of the index system is the evaluation of the operating procedures, which provides a "evaluation of what". In general, the evaluation indicators themselves have a guiding role in teaching, that is, what indicators to evaluate, teachers will attach importance to what indicators. Therefore, the establishment and selection of indicators is extremely important, not only reflects the nature of teaching, select a typical, objective indicators, but also pay attention to the guiding role of advance. The evaluation system of PE teaching evaluation is different from the evaluation system. The evaluation system is more macroscopic and involves all aspects of PE teaching evaluation. The evaluation index system is an important part in the evaluation system. In the evaluation of physical education, the evaluation index system is the concrete of the goal of physical education, can play the role of guiding teaching, but also the specificity of the evaluation objectives, can indicate the evaluation of the main body or teachers should evaluate what, what or ignore what. Evaluation of the index system does not exist or is not perfect, will make the entire teaching evaluation activities are affected. In general, the goal always comes to a certain degree of principle, abstraction and generalization. Therefore, the target is difficult to use as the basis for the assessment. The evaluation index is an aspect of the teaching objectives of the provisions, it is specific, measurable, behavioral and operational goals. Specifically, the content of the indicators can be made by the actual observation of the object to draw a clear conclusion. The nature of the indicator is an important reason for its direct basis for evaluation, and an important basis for judging whether it can become a specific indicator. Compared with the target, indicators tend to have a stronger command orientation. In fact, the dialectical relationship between the indicator and the target decides: "The indicator is not only negatively targeted by the target, but it also actively stipulates that the goal can become a practical goal." From the relationship between the index and the target can be seen in the scientific design of the evaluation of the importance of the index system. Therefore, the evaluation index system is the concrete goal of carrying on the evaluation of physical education and the basis of teaching evaluation, which is the concrete factor which makes the evaluation goal. Although the relationship between the evaluation index and the evaluation goal is very close, but there is still a certain difference between the two, the target response evaluation object of the whole picture, with a certain degree of principle, abstraction, and relatively stable, easy to change, and evaluation Indicators are reflected in the evaluation of the local, with a high degree of specificity and reality, and can reflect the objectives of the premise, 
according to the characteristics of different periods of appropriate changes.

"Weight" refers to the primary and secondary distinction and importance of each evaluation index in the evaluation index system. It is a distinction between the degree of activity time and the distribution of the energy distribution of the object when the distinction is made on the balance of the different quality of the evaluation object. In reality, the understanding of any thing, will not make their different quality for the equivalent of judgments regardless of primary and prior priorities. The evaluation of the same thing, due to the purpose of different objectives, the same indicators can also have different weights. In the evaluation of the same object in the same purpose, it is directly related to whether the object of the evaluation index is accurate or not. Large problem, therefore, to establish the evaluation index system of physical education for the indicators "weight" of the distribution to be given full attention. The general principles of the establishment of the index system should meet the following conditions: consistency with the target: the main embodied in the system within the specific indicators and objectives of the consistency; direct testability: indicators specified by the actual observation can be directly The overall completeness of the index system: the comprehensiveness of the index, which is directly related to the independence of the index system, the scientific nature of the index system, which is consistent with the independence of the index system; Comparability: Indicators must reflect the common attributes of the object to be evaluated for comparison. Acceptability: It is feasible to evaluate the indicators according to the actual level of educational development.

\section{Establish the Principles of Evaluation System of Physical Education Teaching}

The reform of physical education teaching evaluation is to adapt to the needs of curriculum reform. It is aimed at promoting the development of students. It emphasizes the teaching evaluation to promote teachers' improvement and improve the teaching function, and dilutes the screening and selection. The evaluation of PE teaching has the characteristics of paying attention to the teaching process, emphasizing the qualitative evaluation, advocating the evaluation goal and the subject diversity, emphasizing the participation and interaction, and paying attention to the individual difference. Therefore, it is necessary to reflect the concept of PE teaching evaluation in the process of establishing the evaluation index system of physical education The evaluation index system is not only the basis for the evaluation of the evaluation, but also the reference material that the appraiser constantly changes the teaching thought, improves the teaching method and standardizes the teaching behavior.

Physical education is a complex system composed of many elements, but also a dynamic and changing understanding and practice process. The characteristics and curriculum characteristics of PE teaching make it difficult to reflect all the factors and all the factors of the process. Therefore, The evaluation index system should focus on the whole process of teaching, should be based on the concept of physical education teaching evaluation, according to the specific requirements of physical education curriculum design to evaluate the content and elements, to seize the main contradictions, highlight the focus of evaluation, reflecting the substantive tendencies of teaching activities. According to the scientific requirements of the evaluation index system, it is not only compatible with the classification of a certain classification of the objects, the decomposition of the elements of the project, the indicators are mutually exclusive, each indicator independently provides information, can not have overlapping relationship, to avoid Redundant indicators of interference, to ensure the reliability and validity of evaluation.

The evaluation system of physical education should be used to judge the achievement degree of the established teaching goal through the index system. Therefore, the evaluation index system should be the concrete and the behavior of the PE teaching target, the method of measurement and the language of the expression should be operable, Observation, can feel, measurable, evaluable, language to be simple, accurate, easy to operate. 


\section{Conclusion}

China's current school physical education teaching evaluation presents a diversified trend, but there is a contradiction between theory and practice need to be resolved. The results of the empirical survey show that the role of physical education teachers in the evaluation of physical education, the meaning of the full understanding of the evaluation of the main body of diversification, evaluation of content diversity, evaluation methods diversified development trend recognized attitude, and hope to actively put into practice; The majority of students expressed an objective evaluation of themselves and others, the evaluation of physical education and teacher evaluation of the correct understanding, know how to promote teachers and students a common means of progress, But not satisfied with the existing evaluation methods, hoping to be improved. Teachers and students for the correct evaluation of physical education and positive attitude for the evaluation of physical education evaluation provides a good condition.

\section{References}

[1] Gao Xiaoyan. How to strengthen the basic position of skills teaching in physical education curriculum [J]. Journal of Anhui Sports Science and Technology. 2006 (06)

[2] Tan Wenhua, Zhang Li. Shaanxi university sports evaluation evaluation of the status quo [J].Journal of Beijing Sport University. 2005 (07)

[3] Huang Baohong, Wei Dengyun. Study on the Error of Index in Physical Education Teaching Evaluation [J].Journal of Wuhan Institute of Physical Education. 2005 (06)

[4] Cai Ruianguang, Qiu Meiting. Study on evaluation system of college students' physical education [J].Journal of Hebei Normal University (Education Science Edition). 2005 (01)

[5] Zhang Shuwei, Zhang Jinsong. On the establishment of college physical education evaluation system thinking [J].Journal of Liaoning Institute of Technology (Social Science Edition). 2005 (01)

[6] Peng Qingjun, Zhu Lingling. Study on the evaluation model of college sports learning [J].Shandong Sports Science and Technology. 2005 (01) 